07

\title{
Светодиодные структуры на основе ZnO-пленок, полученных методом высокочастотного магнетронного распыления, для УФ области спектра
}

\author{
(C) М.М. Мездрогина, ${ }^{1}$ А.Я. Виноградов, ${ }^{1}$ Ю.В. Кожанова, ${ }^{2}$ E.А. Борсук ${ }^{1}$ \\ ${ }^{1}$ Физико-технический институт им. А.Ф. Иофре РАН, \\ 194021 Санкт-Петербург, Россия \\ ${ }^{2}$ Санкт-Петербургский политехнический университет Петра Великого, \\ 195251 Санкт-Петербург, Россия \\ e-mail: Margaret.m@mail.ioffe.ru
}

Поступило в Редакцию 24 октября 2018 г.

В окончательной редакции 11 января 2019 г.

Принято к публикации 30 сентября 2019 г.

Представлены результаты исследований влияния различных дефектов на вид спектров фото- и электролюминесценции (интенсивность и длину волны излучения) структур $n-\mathrm{ZnO} / p$-GaN.

Ключевые слова: пленки $\mathrm{ZnO}, p-\mathrm{GaN}$, спектры фотолюминесценции в УФ области спектра.

DOI: $10.21883 /$ JTF.2020.03.48931.378-18

\section{Введение}

Необходимость создания эффективных светодиодов (LED) для коротковолновой (УФ) области спектра стимулировала интенсивные исследования широкозонных полупроводников на основе соединений $\mathrm{A}^{\mathrm{III}} \mathrm{B}^{\mathrm{V}}$ (например, $\mathrm{AlN}, \mathrm{GaN}, \mathrm{InGaN}$ ), на основе соединений $\mathrm{A}^{\mathrm{II}} \mathrm{B}^{\mathrm{VI}}(\mathrm{ZnS}, \mathrm{ZnSe})$. Среди $\mathrm{A}^{\mathrm{II}} \mathrm{B}^{\mathrm{VI}}$-соединений оксид цинка ( $\mathrm{ZnO}$ - цинкит, ковалентный кристалл) занимает особое место.

$\mathrm{ZnO}$ - прямозонный полупроводник с шириной запрещенной зоны $E_{g}=3.37 \mathrm{eV}$ интенсивно исследуется в настоящее время в связи с перспективой использования его как полифункционального материала в оптоэлектронных устройствах [1-4], в приборах спинтроники как магнитный материал при легировании $3 d$ примесями, в частности Fe57 [5], солнечных батареях (ФЭП) в качестве прозрачного проводящего слоя [6] при работе с излучением в УФ области спектра.

$\mathrm{ZnO}$ имеет энергию связи свободного экситона $60 \mathrm{meV}$, вследствие чего может быть использован для создания приборов, работающих при повышенных температурах, имеет хорошую радиационную стойкость, это химически стабильный и дешевый материал, который может быть получен многочисленными методами.

Одним из широко используемых способов нанесения пленок $\mathrm{ZnO}$ является метод высокочастотного магнетронного распыления $[7,8]$.

Целью настоящей работы является исследование влияния параметров нанесения пленок $\mathrm{ZnO}$, полученных методом высокочастотного магнетронного распыления, на параметры структур на их основе. Особое внимание уделяется увеличению интенсивности излучения в УФ области спектра с $\lambda=374 \mathrm{~nm}$, соответствующего излучению экситона, связанного с 1LO фононом.
При легировании $\mathrm{ZnO}$ металлическими примесями $\mathrm{Li}$, $\mathrm{Ag}, \mathrm{Au}$ в катионной подрешетке с целью получения пленок с p-типом проводимости, в настоящей работе использован метод диффузии. В качестве легирующего компонента был выбран Li вследствие его большой химической активности, а также вследствие величины ионного радиуса, близкой к величине ионного радиуса $\mathrm{Zn}$ при замещении $\mathrm{Li}$ в полупроводниковой матрице $\mathrm{ZnO}$ точечных дефектов $-V_{\mathrm{Zn}}$. Ранее было показано, что введение газовой примеси - азота $(\mathrm{N})$ в анионную подрешетку дает возможность получения пленок $p$ - $\mathrm{ZnO}$ [8]. $\mathrm{B}$ настоящей работе легирование газовой примесью $\mathrm{N}^{+}$ в анионной подрешетке производилось в процессе отжига пленок $\mathrm{ZnO}$ в высокочастотном (13.56 MHz) газовом разряде смеси азота и аргона при варьировании времени отжига. Концентрацию введенной газовой примеси контролировали с помощью метода ядерных реакций [8].

Известно, что для кристаллической полупроводниковой матрицы $\mathrm{ZnO}$ водород $(\mathrm{H})$ является одной из основных примесей, образующих дефекты донорного типа, поскольку О-Н-связи увеличивают концентрацию собственных дефектов полупроводниковой матрицы, в частности, вследствие изменений стехиометрии. Водород также может образовывать комплексы с другими неконтролируемыми фоновыми примесями, например, с кремнием ( $\mathrm{Si})$.

В настоящей работе, как и в [7], величина концентрации Н в пленках $\mathrm{ZnO}$ была определена методом ИК-спектроскопии.

Известно использование полупроводника $\mathrm{GaN}$ с шириной запрещенной зоны $E_{g}$, равной $3.43 \mathrm{eV}$, энергией связи свободного экситона $25 \mathrm{meV}$, рассогласованием постоянной решетки не более $1.9 \%$ по отношению к величине постоянной решетки $\mathrm{ZnO}$ при создании светоизлучающих структур на основе пленок $\mathrm{ZnO}$ [5-8]. 
Параметры нанесения пленок $\mathrm{ZnO}$. Материал подложки $-\mathrm{Si}, \mathrm{SiO}_{2}$

\begin{tabular}{c|c|c|c|c|c}
\hline $\begin{array}{c}\text { Номер } \\
\text { пленки } \\
\mathrm{ZnO}\end{array}$ & $\begin{array}{c}\text { Давление газовой } \\
\text { смеси Ar+ O, } \\
\text { Torr }\end{array}$ & $\begin{array}{c}\text { Температура } \\
\text { подложки, } \\
{ }^{\circ} \mathrm{C}\end{array}$ & $\begin{array}{c}\text { ВЧ } \\
\text { мощность, } \\
\mathrm{W}\end{array}$ & $\begin{array}{c}\text { Время } \\
\text { нанесения, } \\
\text { mіn }\end{array}$ & $\begin{array}{c}\text { Наличие } \\
\text { плавающего } \\
\text { потенциала }\end{array}$ \\
\hline 1 & $4.4 \cdot 10^{-2}$ & 610 & 40 & 30 & \\
2 & $4.6 \cdot 10^{-2}$ & 500 & 40 & 30 & нет \\
3 & $4.6 \cdot 10^{-2}$ & 640 & 40 & 30 & да \\
4 & $4.7 \cdot 10^{-2}$ & 510 & 40 & 90 & нет \\
5 & $4.5 \cdot 10^{-2}$ & 640 & 40 & 90 & на
\end{tabular}

Для нанесения пленок $\mathrm{GaN}$ в настоящее время наиболее распространенными методами являются молекулярно-пучковая эпитаксия (MBE), осаждение металлорганических соединений из газовой фазы (MOCVD), гидридная газофазная эпитаксия (HVPE), а также методы лазерной абляции подложки, нанесения буферного слоя перед нанесением слоев $\mathrm{GaN}$ [9-13].

\section{Эксперимент}

Слой $\mathrm{GaN}$, легированный $\mathrm{Mg}(\mathrm{GaN}\langle\mathrm{Mg}\rangle$ с $p$-типом проводимости, далее $p$-GaN), толщиной $270 \mathrm{~nm}$ был выращен на буферном нелегированном слое GaN. Параметры пленок $p$-GaN исследованы с помощью измерений эффекта Холла (методика Ван-дер-Пау), измерений спектров фотолюминесценции (ФЛ) и атомно-силовой микроскопии. Поверхность пленок $p-\mathrm{GaN}$, использовавшихся в настоящей работе в качестве подложек, не подвергалась какой-либо обработке перед последующим нанесением пленок $n$ - $\mathrm{ZnO}$.

$\mathrm{B}$ настоящей работе пленки $\mathrm{ZnO}$ при изготовлении структур $n-\mathrm{ZnO} / p$-GaN, $p$ - $\mathrm{ZnO} / n-\mathrm{ZnO}$ получены методом высокочастотного магнетронного распыления мишени в смеси газов $\mathrm{Ar}$ с $\mathrm{O}_{2}$ на подложках из различных материалов: $p-\mathrm{GaN}: \mathrm{Mg} / \mathrm{GaN} / \mathrm{Al}_{2} \mathrm{O}_{3}$, кристаллического кремния с $p$-типом проводимости марки КДБ-10, кристаллических пленок $c-\mathrm{ZnO}$, выращенных гидротермальным или газофазным методом.

Ранее на основании измерений методом комбинационного рассеяния было показано, что пленки $\mathrm{ZnO}$, полученные высокочастотным магнетронным распылением, являются кристаллическими. В спектрах комбинационного рассеяния пленок $\mathrm{ZnO}$ наблюдаются сильные полосы с максимумами вблизи $\omega_{E 2}^{H i g h} \sim 437 \mathrm{~cm}^{-1}$, т.е. нанесенный $\mathrm{ZnO}$-слой действительно имеет вюрцитную гексагональную кристаллическую структуру, а присутствие полосы $\omega_{\mathrm{A} 1}(\mathrm{LO}) \sim 580 \mathrm{~cm}^{-1}$ указывает на наличие собственных дефектов решетки. Кроме того, в спектрах комбинационного рассеяния наблюдаются более слабые линии на $\omega=101,276,327,509,720$ и $1150 \mathrm{~cm}^{-1}$ : полоса с максимумом $\omega=101 \mathrm{~cm}^{-1}$ соответствует моде $\omega_{E 2}^{L o w}$, линия с максимумом $\omega=276 \mathrm{~cm}^{-1}$ соответствует моде $B_{2}$ и указывает на наличие встроенного электрического поля в области обеднения. Полоса с максимумом $\omega=720 \mathrm{~cm}^{-1}$ указывает на наличие примесей $\mathrm{Fe}$, с максимумом $\omega=509 \mathrm{~cm}^{-1}$ соответствует моде $\mathrm{A}_{1}(\mathrm{LO})$. Полосы с $\omega=327$ и $1150 \mathrm{~cm}^{-1}$ указывают на процессы мультифононного рассеяния $\left(E_{2 H}-E_{2 L}\right)$ и 2LO, возникающая при связи LO-фононов со свободными носителями соответственно. Линия $\omega=568 \mathrm{~cm}^{-1}$ возникает из подложки $\mathrm{GaN}$ и соответствует $E_{2}^{\text {High }}$-моде.

На основании измерений спектров ФЛ пленок $\mathrm{ZnO}$ было показано, что длина волны излучения $\left(\lambda_{\max }\right)$ несущественно меняется при изменении материала подложки, меняется лишь интенсивность излучения, т.е. меняется концентрация дефектов. Было показано так же, что уменьшение скорости нанесения до $0.1 \mathrm{~nm} / \mathrm{s}$ дает возможность регистрации спектров ФЛ с малой величиной FWHM, т.е. однородных по площади подложки вследствие реализации процессов самоорганизации [8].

В настоящей работе исследовано влияние дальнейшего уменьшения скорости нанесения пленок $\mathrm{ZnO}$ методом высокочастотного магнетронного распыления с целью увеличения размеров зерна, с целью повышения однородности пленок, увеличения интенсивности излучения в УФ области спектра.

Изменение параметров осаждения (давления газовой смеси, температуры и потенциала подложки, высокочастотной мощности) на скорость нанесения пленок $\mathrm{ZnO}$ дала возможность варьирования скорости от 0.005 до $0.065 \mathrm{~nm} / \mathrm{s}$. Наличие плавающего потенциала на подложке при использовании метода высокочастотного магнетронного распыления не приводит к уменьшению скорости нанесения пленок $\mathrm{ZnO}$ (см. таблицу).

Морфология поверхности исследуемых в настоящей работе пленок $\mathrm{ZnO}$ определялась как материалом подложки, так и параметрами осаждения.

Показано, что во всех используемых в настоящей работе процессах при малой скорости нанесения, которая не превышала $0.06 \mathrm{~nm} / \mathrm{s}$, размер зерна не превышал $2-3 \mathrm{~nm}$ на подложке из кварца $\left(\mathrm{SiO}_{2}\right)$ и $3-3.5 \mathrm{~nm}$ на подложке из $\mathrm{Si}$ (КДБ-10). Таким образом, уменьшение скорости нанесения не привело к какому-либо существенному изменению размеров зерна, поскольку механизм нанесения пленок не изменился и соответствовал механизму пар-кристалл ( $3 D$-механизм), т.е. не реализовался механизм движения зародышей $\mathrm{ZnO}$-пленки по поверхности подложки, который, как правило, имеет ме- 


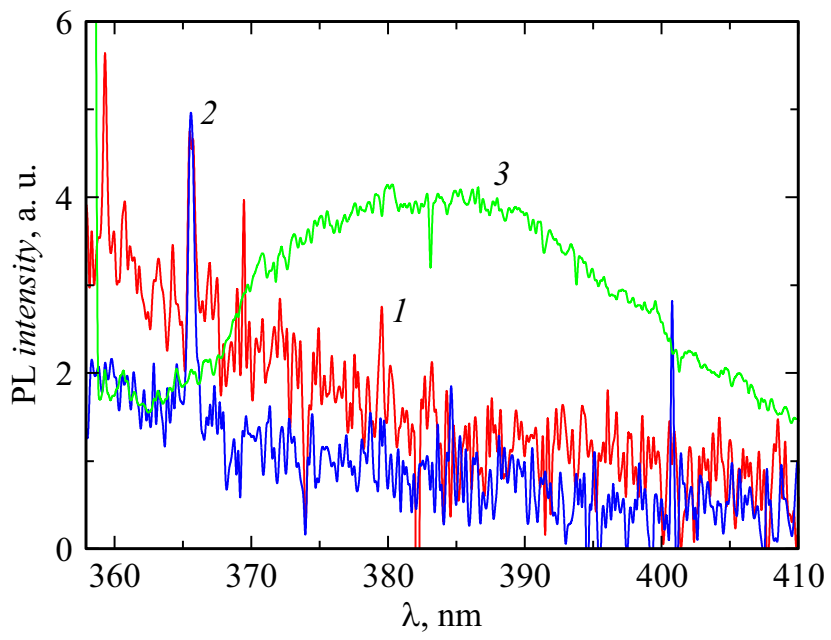

Рис. 1. Спектры ФЛ, снятые при температуре $78 \mathrm{~K}$, пленок $\mathrm{ZnO}$, полученных при разных температурах $(T)$ нанесения: $1-610,2-615,3-500^{\circ} \mathrm{C}$.

сто при реализации механизма пар-жидкость-кристалл (2D-механизм) [8-11]. В то же время увеличение температуры осаждения (до $T=610^{\circ} \mathrm{C}$ ) приводит к изменению вида спектров - появлению пиков излучения в спектрах ФЛ указанных пленок в коротковолновой области (рис. $1-$ ср. кривые $1\left(T=610^{\circ} \mathrm{C}\right), 2\left(T=615^{\circ} \mathrm{C}\right)$ с кривой $3\left(T=500^{\circ} \mathrm{C}\right)$.

Очевидно, что подвижность и концентрация носителей заряда в нанесенных пленках $\mathrm{ZnO}$ будет определяться размерами зерна, межзеренными границами. Весьма существенное уменьшение скорости нанесения при использовании метода высокочастотного магнетронного распыления $(<0.05 \mathrm{~nm} / \mathrm{s})$ не привело к увеличению размеров зерна, он остался равным 3-3.5 nm, как и при большей скорости нанесения - $1 \mathrm{~nm} / \mathrm{s}$.

Уменьшение скорости нанесения, температуры подложки способствует, как правило, увеличению концентрации дефектов полупроводниковой матрицы $\mathrm{ZnO}$.

Морфологию поверхности пленок $\mathrm{ZnO}$ вне зависимости от легирования, методики получения (MBE, метод высокочастотного магнетронного распыления) можно интерпретировать как столбчатую структуру, в которой величины неоднородностей в горизонтальном и вертикальном направлениях одинаковы. Вследствие роста по механизму пар-кристалл (3D-механизм), неоднородность морфологии поверхности в пленках, полученных MBE-методом, в вертикальном направлении практически совпадает с неоднородностью поверхности пленок $\mathrm{ZnO}$, полученных методом высокочастотного магнетронного распыления.

В то же время интерфейс между пленкой $n-\mathrm{ZnO}$, $p$-GaN, КДБ-10 содержит большую плотность структурных протяженных дефектов (дислокаций) из-за наличия упругих напряжений несоответствия на границе слоев вследствие разницы в параметрах кристаллических решеток $\mathrm{ZnO}, \mathrm{GaN}$, -Si [12-14].
Ранее была исследована морфология поверхностей пленок $p$ - $\mathrm{GaN}$ и структур $n-\mathrm{ZnO} / p-\mathrm{GaN}$ с помощью атомно-силовой микроскопии $[7,8]$. Показано, что исходная поверхность пленок $p$-GaN существенно отличается от планарной и имеет неоднородности до $200 \mathrm{~nm} \mathrm{в}$ латеральной плоскости и до $40-50 \mathrm{~nm}$ в глубину, что определяло кинетику роста последующих слоев $\mathrm{ZnO}$ при реализации механизма пар-кристалл, следовательно, впоследствии параметры нанесенных пленок.

Характерный размер неоднородностей на поверхности нанесенных пленок $\mathrm{ZnO}$ : в плоскости - $200 \mathrm{~nm}$, в перпендикулярном направлении - 40-60 nm, в пленки $n-\mathrm{ZnO}$ дефекты прорастают из подложки $p-\mathrm{GaN}$.

В пленках $p$-GaN, используемых в качестве подложек при нанесении пленок $n-\mathrm{ZnO}$, были измерены (Ван-дер-Пау методика измерений) тип, концентрация и подвижность носителей заряда. Пленки $p-\mathrm{GaN}$ имели проводимость $p$-типа с концентрацией неосновных носителей заряда, равной $9.7 \cdot 10^{18} \mathrm{~cm}^{-3}$, с подвижностью носителей заряда, равной $12 \mathrm{~cm}^{2} /(\mathrm{V} \cdot \mathrm{s})$.

Были исследованы характеристики слоев $\mathrm{ZnO}$, нанесенных методом высокочастотного магнетронного распыления; пленки были $n$-типа проводимости с подвижностью $45 \mathrm{~cm}^{2} /(\mathrm{V} \cdot \mathrm{s})$, концентрацией электронов $1.58 \cdot 10^{18} \mathrm{~cm}^{-3}$.

Спектры ФЛ гетероструктур $n-\mathrm{ZnO} / p-\mathrm{GaN}$, приведенные на рис. 2, были измерены при температуре $300 \mathrm{~K}$. В качестве источника излучения при измерении спектров ФЛ использовался YAG-лазер с длиной волны $244 \mathrm{~nm}$. В спектрах ФЛ гетероструктур $n-\mathrm{ZnO} / p-\mathrm{GaN}$ (рис. 2) имеются ярко выраженные линии излучения, связанные с рекомбинацией свободных $(\lambda=363 \mathrm{~nm})$ и связанных экситонов $(\lambda=377,390,410 \mathrm{~nm})$. Следует отметить, что в области примесной ФЛ с $\lambda=450-600 \mathrm{~nm}$ существенного излучения не наблюдалось, т.е. концентрация точечных дефектов $V_{\mathrm{Zn}}, V_{\mathrm{O}}$, определяющих интенсивность излучения в данной области спектра, была незначительна [9-12].

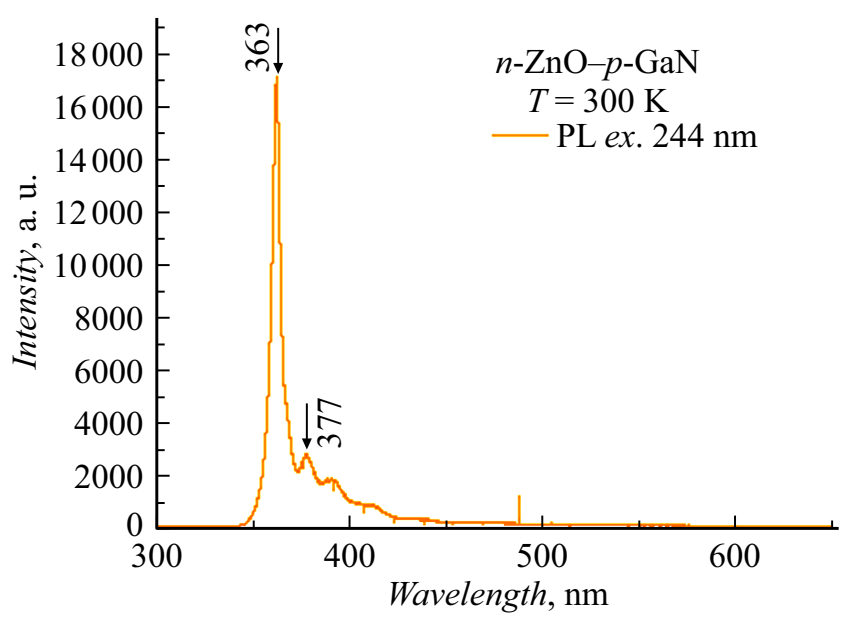

Рис. 2. Спектр ФЛ $(300 \mathrm{~K})$ структуры $n-\mathrm{ZnO} / p-\mathrm{GaN}$. 


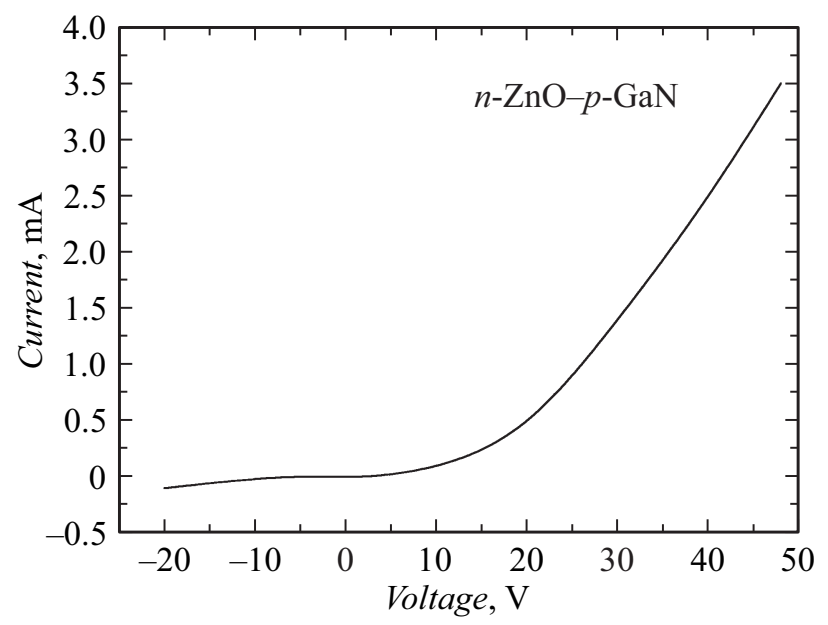

Рис. 3. BAX структуры $n-\mathrm{ZnO} / p-\mathrm{GaN}(300 \mathrm{~K})$.

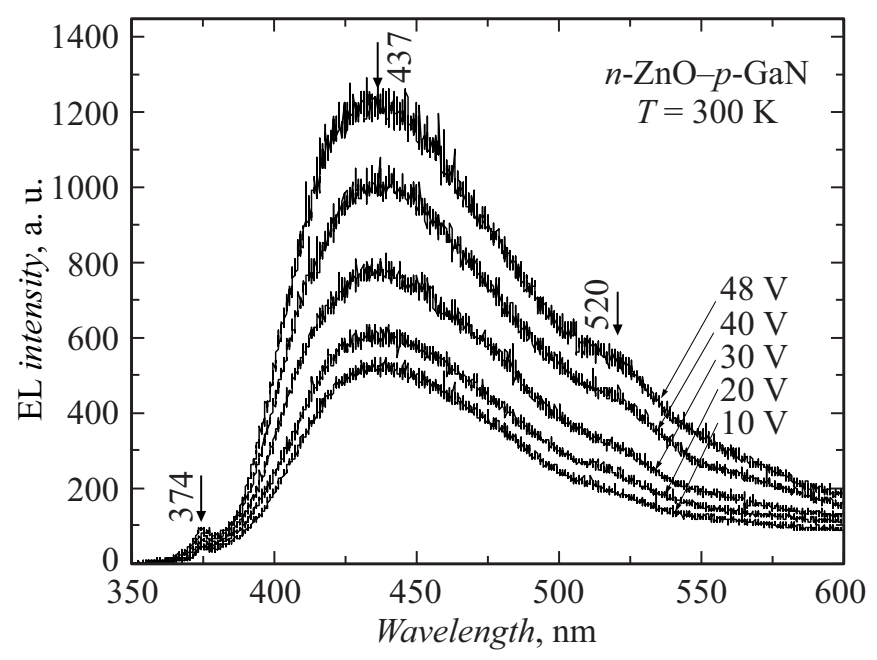

Рис. 4. Спектры ЭЛ структуры $n-\mathrm{ZnO} / p-\mathrm{GaN}$.

Вольт-амперная характеристика (BAX) структуры $n-\mathrm{ZnO} / p$-GaN, приведенная на рис. 3, имеет форму, свойственную качественному $n-p$-переходу [13-16]. В то же время наблюдаются малые величины токов и довольно высокие значения напряжения отсечки $\left(U_{\text {Cutoff }}\right)$, необходимые для получения излучения из данных структур, что может свидетельствовать об особенностях энергетической диаграммы, особенностях морфологии поверхности интерфейса - наличия столбчатой структуры или промежуточных диэлектрических слоев, что, возможно, и определяет большие величины $U_{\text {Cutoff. }}$ Подобные значения величин $U_{\text {Cutoff }}$ более характерны для наностержней $\mathrm{ZnO}$, выращенных на слое $\mathrm{GaN}[2-4]$.

В то же время нельзя исключить и механизм возникновения электрического поля на гетерогранице $n-\mathrm{ZnO} / p-\mathrm{GaN}$, а также влияния присутствия промежуточных диэлектрических слоев [16-18].

Измерения спектров электролюминесценции (ЭЛ) проводились на дифракционном спектрометре СДЛ-2 с обратной линейной дисперсией $1.3 \mathrm{~nm} / \mathrm{mm}$ в области излучения структур, исследуемых в настоящей работе. Спектральное разрешение (щели) при записи спектров составляло $0.26 \mathrm{~nm}$. Экспериментальные данные по зависимости ЭЛ от напряжения представлены на рис. 4.

Как видно из рис. 4 , полоса излучения в спектре ЭЛ структуры $n-\mathrm{ZnO} / p$-GaN имеет максимум с $\lambda=437 \mathrm{~nm}$, т. е. соответствует длине волны излучения, характерной для структур с множественными квантовыми ямами на основе InGaN/GaN [5-8]. Кроме того, имеются выраженные, но значительно менее интенсивные максимумы с $\lambda=374$ и $520 \mathrm{~nm}$.

При увеличении подаваемого напряжения наблюдается несущественное изменение положения максимума излучения. Подобный результат наблюдался ранее, что характерно для особенностей формирования $p-n$-перехода в подобных структурах. Наличие пиков с максимумом $\lambda=374 \mathrm{~nm}$ с малой интенсивностью, вероятнее всего, соответствует рекомбинации носителей в слое $n-\mathrm{ZnO}$, что соответствует положению экситона, связанного с 1LO-фононом [11-13] .

C учетом данных, полученных с помощью спектроскопии комбинационного рассеяния (наличие $B$-моды) и атомно-силовой микроскопии (AFM), можно предположить, что интерфейсный слой $n-\mathrm{ZnO}$ на границе с $p-\mathrm{GaN}$ сильно напряжен. Известно, что слои $n-\mathrm{ZnO}$ и $p-\mathrm{GaN}: \mathrm{Mg}$ являются пьезоэлектриками, вследствие чего возникает электрическое поле на границе $n-p$-гетероперехода, т. е. спектры ЭЛ можно наблюдать, начиная с $10 \mathrm{~V}$ ( $\left.U_{\text {Cutoff }}\right)$, интенсивность ЭЛ возрастает с увеличением подаваемого напряжения вплоть до $50 \mathrm{~V}$.

На рис. 5 приведена зависимость интенсивности излучения с максимумом $\lambda=374 \mathrm{~nm}$ от тока. Данная зависимость имеет линейный характер, что указывает на незначительное влияние безызлучательных дефектов полупроводниковой матрицы $\mathrm{ZnO}$ на интенсивность излуче-

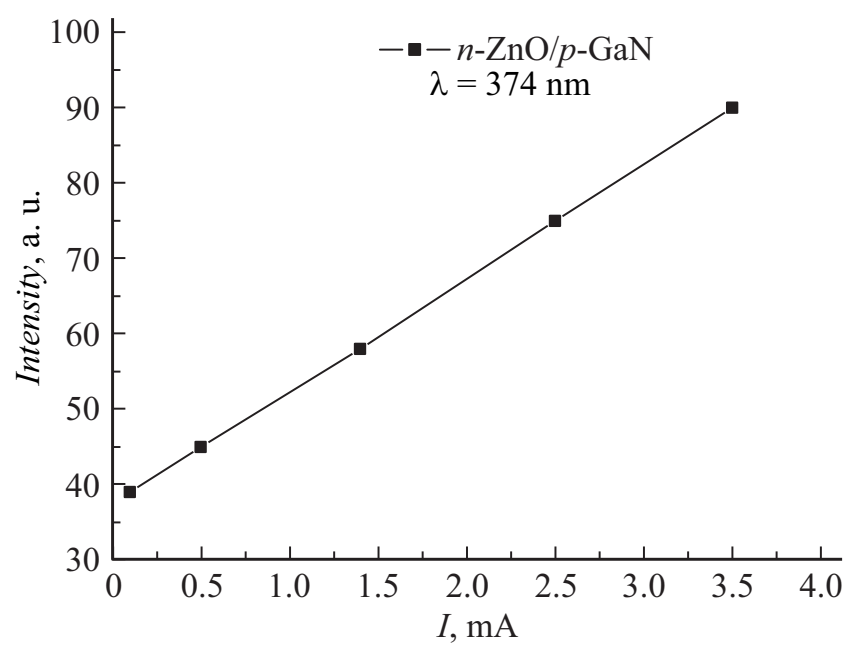

Рис. 5. Зависимость интенсивности излучения $\lambda=374 \mathrm{~nm}$ структуры $n-\mathrm{ZnO} / p$-GaN от тока. 


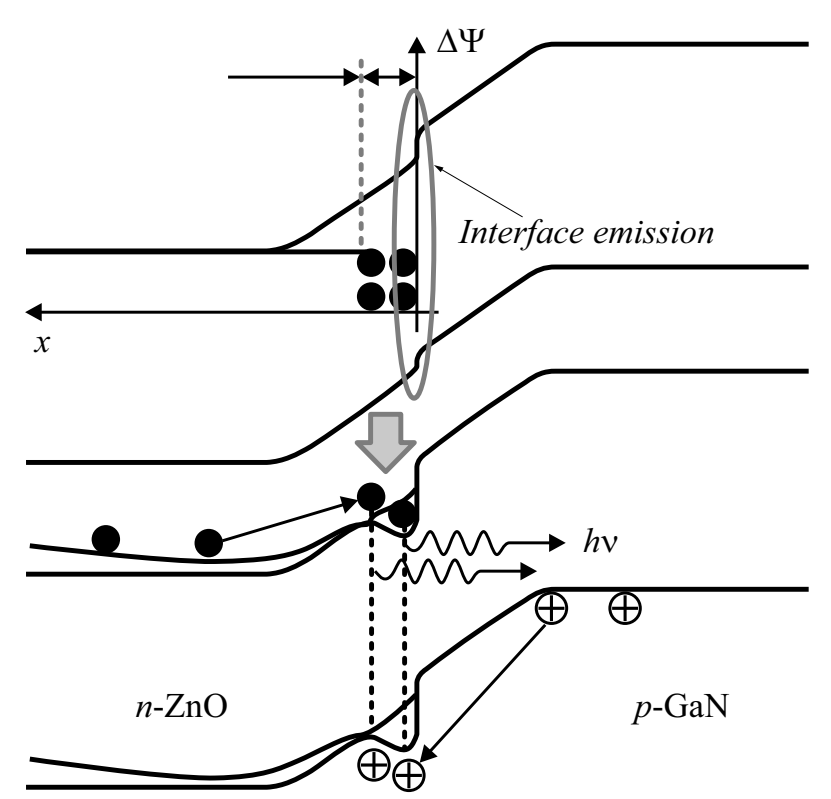

Рис. 6. Гипотетическая энергетическая диаграмма структуры $n-\mathrm{ZnO} / p-\mathrm{GaN}$.

ния, а также означает, что механизм рекомбинации определяется напряжениями $p-n$-гетероперехода [12-14].

Для объяснения экспериментальных данных целесообразно рассмотреть гипотетическую энергетическую диаграмму исследуемой структуры (рис. 6). Предполагается, что вследствие наличия значительных напряжений на интерфейсе образуется потенциальная яма для электронов. Это приводит к тому, что электроны, имеющие большую подвижность в слое $n-\mathrm{ZnO}$, не успевают проникать в слой $p$-GaN с достаточной концентрацией, поэтому они рекомбинируют в слое $\mathrm{GaN}$. Дырки же, напротив, даже имея небольшую величину подвижности, успевают добраться до границы интерфейса и даже частично в слой $n-\mathrm{ZnO}$ и там рекомбинировать. Высказанное предположение может быть подтверждено также аппроксимацией гауссовыми функциями вида спектра ЭЛ структур $n-\mathrm{ZnO} / p-\mathrm{GaN}$.

Полоса с максимумом $\lambda=412 \mathrm{~nm}$ соответствует излучению на интерфейсе (интерфейсной эмиссии), полоса с $\lambda=437 \mathrm{~nm}$ связана с переходами, характерными для $p$-GaN. Желтая с $\lambda \approx 520 \mathrm{~nm}$ связана с дефектами решетки $\mathrm{ZnO}$ - вакансиями кислорода $V_{\mathrm{O} 2}$ или вакансиями цинка $V_{\mathrm{Zn}}$. Линии излучения $\lambda=475$ и $553 \mathrm{~nm}$ связаны с дефектами решетки $\mathrm{GaN}$ [15-18]. Соотношение интенсивностей полученных полос излучения косвенно подтверждает вышеприведенный вывод.

Исследованы параметры спектров ФЛ структур $n-\mathrm{ZnO} / p$ - $\mathrm{ZnO}$, выращенных на подложках из кристаллического $c$ - $\mathrm{ZnO}$ методом высокочастотного магнетронного распыления.

Величина внутренней квантовой эффективности (ВКЭ) излучательной рекомбинации структур $p-\mathrm{ZnO} / n-\mathrm{ZnO}$, учитывающей не только эффективность инжекции носителей, но и конкуренцию излучательного и безызлучательного каналов их рекомбинации, мала вследствие большой концентрации дефектов и примесей в исходной полупроводниковой матрице $\mathrm{ZnO}$ [11-13].

В данных структурах ВАХ имели напряжение отсечки не менее $6 \mathrm{~V}$. Такая относительно большая величина $U_{\text {Cutoff }}$ может быть обусловлена вероятным наличием диэлектрического слоя $(\mathrm{Li}-\mathrm{O}, \mathrm{Li}-\mathrm{H})$ на гетерогранице $n-\mathrm{ZnO} / p-\mathrm{ZnO}$. Диэлектрический слой может возникать на поверхности слоя $p-\mathrm{ZnO}$ вследствие избыточной концентрации $\mathrm{Li}, \mathrm{N}$ при легировании пленок $n-\mathrm{ZnO}$ для реализации дырочного типа проводимости, а также примеси Н в пленках $n-\mathrm{ZnO}$.

В спектрах ФЛ исследованных структур $n-\mathrm{ZnO} / p-\mathrm{ZnO}$ присутствуют пики излучения с максимумом $\lambda=374 \mathrm{~nm}$ с незначительной интенсивностью, т.е. излучение в более коротковолновой области УФ спектра, чем в ранее исследованных структурах $\mathrm{InGaN} / \mathrm{GaN}$ вне зависимости от изменения в концентрации In.

Увеличение интенсивности излучения с $\lambda=374 \mathrm{~nm}$ актуально при разработке новых полупроводниковых структур для лазеров, работающих в УФ диапазоне, при решении задачи увеличения плотности записи в литографических процессах.

Увеличение интенсивности данной линии излучения $\lambda=374 \mathrm{~nm}$ может быть реализовано в результате комплекса мер - при детальной оптимизации технологии роста, кинетики роста пленок, легирования слоев $\mathrm{ZnO}$, уменьшении концентрации ловушек для электронов.

Использование монокристаллического кремния КДБ-10 в качестве $p$-слоя для создания структур на основе $n-\mathrm{ZnO}$ может позволить увеличить интенсивность излучения в УФ области вследствие увеличения подвижности неосновных носителей заряда при оптимизации энергетической диаграммы гетероперехода. В то же время наличие протяженных дефектов на границе $n-\mathrm{ZnO} / p$-Si вследствие присутствия напряжений несоответствия не будут способствовать созданию оптимальной энергетической диаграммы гетероперехода, т. е. увеличению интенсивности излучения в коротковолновой области спектра.

Вид BAX структур $n-\mathrm{ZnO} / p-\mathrm{ZnO}$ характерен $p$-n-структур, но с малыми величинами токов и больших напряжений отсечки [12-18].

\section{Обсуждение результатов}

Увеличение интенсивности излучения в УФ $(\lambda=$ $=374 \mathrm{~nm})$ и видимой $(\lambda=437 \mathrm{~nm})$ областях спектра в структурах на основе $n-\mathrm{ZnO} / p-\mathrm{ZnO}, n-\mathrm{ZnO} / p$-GaN может быть достигнуто при сушественном уменьшении концентрации дефектов полупроводниковой $\mathrm{ZnO}$-матрицы, а также дефектов на гетерогранице $[19,20]$. 


\section{Заключение}

Вид спектров комбинационного рассеяния подтверждает наличие вюртцитной кристаллической структуры пленок $n-\mathrm{ZnO}$, нанесенных методом магнетронного распыления. В спектрах ФЛ $(T=300 \mathrm{~K})$ структур $p-\mathrm{GaN}: \mathrm{Mg} / n-\mathrm{ZnO}$ наблюдались ярко выраженные линии излучения, связанные с рекомбинацией свободных $(\lambda=363 \mathrm{~nm})$ и связанных $(\lambda=377,390,410 \mathrm{~nm})$ экситонов, в области примесной ФЛ $(\lambda=450-600 \mathrm{~nm})$ существенного излучения не наблюдалось.

\section{Конфликт интересов}

Авторы заявляют, что у них нет конфликта интересов.

\section{Список литературы}

[1] Lupan O., Pauporte T., Viana B. // Adv. Mater. 2010. Vol. 22. P. 3298.

[2] Wang T., Wu H., Wang Z., Chen C., Liu C. // Appl. Phys. Lett. 2012. Vol. 101. P. 161905.

[3] Huang H.H., Fang G.J., Mo X.M., Long H., Wang H.N., Li S.Z., Li Y., Zhang Y.P., Pan C.X., Caroll D.L. // Appl. Phys. Lett. 2012. Vol. 101. P. 223504.

[4] Chichibu S.F., Ohmori T., Shibata N., Koyama T., Onuma T. // Appl. Phys. Lett. 2004. Vol. 85. P. 013509.

[5] Мездрогина М.М., Еременко М.В., Смирнов А.Н., Петров В.Н., Теруков Е.И. // ФТП. 2015. Т. 49. Вып. 8. С. 1016.

[6] Huang H.H., Fang G.J., Li Y., Li S.Z., Mo X.M., Long H., Wang H.N., Caroll L., Zhao X.Z. // Appl. Phys. Lett. 2012. Vol. 100. P. 233502.

[7] Iwan S., Bambeng S., Zhao J.L., Tan S.T., Fan H.M., San L., Zhang S., Ryu H.H., Sun X.W. // Physica. B. 2012. Vol. 407. P. 2721.

[8] Мездрогина М.М., Виноградов А.Я., Левицкий В.С., Терукова Е.Е., Кожанова Ю.В., Агликов А.С. // ФТП. 2017. T. 51. Вып. 5. С. 588.

[9] Мездрогина М.М., Еременко М.В., Левичкий В.С., Петров В.Н., Теруков Е.И., Кайдышев Е.М., Лянгузов Н.В. // ФТП. 2015. Т. 49. Вып. 11. С. 1016.

[10] Мездрогина М.М., Виноградов А.Я., Кожанова Ю.В. // ФТП. 2018. Т. 52. Вып. 10. С. 1115.

[11] Мездрогина М.М., Еременко М.В., Голубенко С.М., Разумов С.М. // ФТТ. 2012. Т. 54. Вып. 6. С. 1155.

[12] Li S.Z., Lin W.W., Fang G.I., Huang F., Huang H.H., Long H., Mo X.M., Wang H.N., Guan W.J., Zhao X.Z. // J. Lumin. 2013. Vol. 140. P. 110.

[13] Alilov Y.I., Van Nostrand J.E., Look D.C., Chukichev M.V., Ataev B.M. // Appl. Phys. Lett. 2003. Vol. 83. P. 2943.

[14] Jeong M.-Ch., Oh B.-Y., Ham M.-H., Myong J.-M. // Appl. Phys. Lett. 2006. Vol. 88. P. 202105.

[15] Dellivers T., Leite D.M.G., Dias da Silva J.H., Bonanni A. // Appl. Phys. Lett. 2013. Vol. 103. P. 211909.

[16] Avramenko K.A., Romanjuk A.S., Strelchuk V.V., Kolomys O.F., Zavialova L.V., Sveshnikov S.V., Snopok B.A.,.Roshina N.N. Pros. Interna. Conf. Nanomaterials: Applications and Properties. 2012. Vol. 1. N 3. P. 03TF12.

[17] Rogers D., Teherani F.H., Yasan A., Minder K., Kung P., Razehi M. // Appl. Phys. Lett. 2006. Vol. 88. P. 141918.
[18] Yuk J.M., Lee J.Y., Jung J.H., Kim T.W., Son D.I., Choi W.K. // Appl. Phys. Lett. 2007. Vol. 90. P. 031907.

[19] Han S.K., Hong S.K., Lee J.W., Song J.H., Nam Y.S., Chang S.K., Minegishi T., Yao T. // J. Cryst. Growth. 2007. Vol. 309. P. 121.

[20] Reshnikov M., Markos H. // J. Appl. Phys. 2009. Vol. 97. P. 061301. 